\title{
THE EFFECT OF ZINC STEARATE ON THERMAL DEGRADATION OF PARAFFIN WAX
}

\author{
M. Gönen, D. Balköse*, F. Inal and S. Ülkü \\ Department of Chemical Engineering, İzmir Institute of Technology, Gülbahçe Köyü-Urla, 35430 İzmir, Turkey
}

\begin{abstract}
In this research, the effects of zinc stearate addition on paraffin wax degradation were investigated by differential scanning calorimetry (DSC) and thermogravimetry (TG). The apparent activation energies of wax decomposition in nitrogen and air atmospheres were determined as 76 and $37 \mathrm{~kJ} \mathrm{~mol}^{-1}$, respectively applying Kissinger method to TG data. The degradation rate constants of paraffin containing zinc stearate $(0.1-0.5 \%)$ were found to be almost two times greater than that of paraffin only in air atmosphere. However, zinc stearate did not affect the rate constants in nitrogen significantly.
\end{abstract}

Keywords: activation energy, Kissinger method, paraffin wax, thermal degradation, zinc stearate

\section{Introduction}

Petroleum waxes are complex mixtures of high molecular mass saturated hydrocarbons. These hydrocarbon mixtures mainly consist of $n$-, iso-, and cyclo-alkanes and traces of aromatic and hetero-analogous compounds in the range of C16-C65 $[1,2]$. They are mainly divided into two groups, macrocrystalline and microcrystalline waxes, according to their structural constituents. In refining industry, waxes are obtained as a by-product in lubricating oil manufacturing process. As paraffin waxes have excellent properties, such as water-repellency and lubricity they find a wide range of applications including paper and chipboard production, packaging materials, cosmetic and pharmaceutical industries, and plastic industries [2]. Apart from these, they are also used as a component of binder system in ceramic processing, metal powder molding and metal injection molding [3, 4]. A technical grade paraffin wax was used as phase change material in deposition of solar energy due to its high latent heat of melting (i.e., $190 \mathrm{~kJ} \mathrm{~kg}^{-1}$ ) [5]. In most of its applications, thermal decomposition takes place during processing or sintering, such as ceramic or metal powder molding. Another use of paraffin wax is solid fuel for rocket systems. Recently, it has been studied as a high regression rate propellant. It is a candidate for rocket solid fuel, which is expected to replace the conventional rocket fuels, such as cryogenic combustible gases; polymethyl methacrylate (PMMA), high density polyethylene (HDPE), due to its low cost, reduced complexity and increased performance. It has been pointed out that paraffin wax regression rate is about $0.100 \mathrm{~cm}^{-1}$, which is five times greater than the other solid hybrid fuels [6]. The thermal decomposition kinetics of RP-1 rocket propellant, which consists of paraffins, olefins and aromatics, was investigated between $375-500^{\circ} \mathrm{C}$. Thermal decomposition kinetics of RP-1 was assumed to occur by first order reaction [7].

Paraffin molecules having different chain length behave similarly towards most of the reactants under similar reaction conditions. When they are heated, they start to degrade into smaller chain lengths. The degradation of petroleum based material is assumed as first order reactions [8].The chain length can be decreased by high temperature treatment and solids having metal ions that act as catalysts. Paraffins in oxidizing media at high temperature undergo simultaneous pyrolysis and oxidation reactions. Pyrolysis of $n$-hexadecane, considered as paraffinic substance, was studied by Watanabe et al. at $500-550^{\circ} \mathrm{C}$ in a batch type closed reactor [9]. There were five elementary reaction groups in the pyrolysis of $n$-hexadecane; initiation, isomerization, $\beta$-scission, $\mathrm{H}$-abstraction and termination. In this mechanism, $n$-alkanes were produced from $\mathrm{H}$-abstraction and $l$-alkenes are formed via $\beta$-scission [9]. Polyethylene which is a polymeric paraffin was converted to liquid and wax products using zeolite with concentrations up to maximum mass by $50 \%$ [10]. Organometallic compounds are added to fuels in small quantities to increase combustion efficiency due to energy conservation and environmental consideration. Addition of organometallic compounds, such as $\mathrm{Mn}, \mathrm{Mg}, \mathrm{Cu}$ and $\mathrm{Ca}$ into diesel fuel was studied by Gürü et al. [11]. They found that organometallic additives improved the diesel fuel properties; especially manganese lowers the

* Author for correspondence: devrimbalkose@iyte.edu.tr 
viscosity and flash point and decreases the concentration of undesired components in exhaust gases. The addition of copper containing organometallic complexes into diesel fuel was found to decrease the ignition temperature of exhaust particles called diesel soot [12]. It was reported that the molar $\mathrm{CO}_{2} / \mathrm{CO}$ ratio of fuel combustion increased with the addition of metallic salts, such as magnesium and copper chlorides [13]. The combustion catalysts are required for paraffin wax candles. Most of these combustion catalysts that are added to the wick of the candle are lead compounds. However, exposure to emissions of candles having lead in their wick is dangerous for human health [14]. A lead free combustion catalyst such as zinc stearate could be added to candle wax to provide safer environment to users.

In most of the paraffin decomposition studies the temperature ranges were above the critical temperature of the paraffin. Thus, gas phase pyrolysis data at high pressures was reported. However, in some of the practical applications of paraffin, pyrolysis and combustion occur at atmospheric pressure. Therefore, the liquid phase pyrolysis should also be taken into consideration. Thermogravimetric analysis is a well known technique to study the pyrolysis of nonvolatile liquids. In addition differential scanning calorimetry could show the energy changes taking place within pyrolysis. The object of this study was to investigate the effects of zinc stearate addition (0.1-0.5 mass $\%)$ to paraffin wax on the rate of thermal degradation in nitrogen and air atmospheres using thermogravimetric analysis and differential scanning calorimetry.

\section{Experimental}

\section{Materials}

Technical grade paraffin wax, manufactured by a local commercial company (Baykim Chemical Industry, Turkey), and zinc stearate $\left(\mathrm{ZnSt}_{2}\right)$, produced in our laboratories by precipitation process, were used in thermal degradation experiments. The melting point of the paraffin wax and $\mathrm{ZnSt}_{2}$ were determined by heating the samples from ambient temperature to $200^{\circ} \mathrm{C}$ using DSC (Shimadzu-50) at a rate of $10^{\circ} \mathrm{C} \mathrm{min}^{-1}$ under $40 \mathrm{~cm}^{3} \min ^{-1} \mathrm{~N}_{2}$ flow. The reported properties of paraffin given by Baykim are as following: melting point $56-58^{\circ} \mathrm{C}$, oil content lower than $1 \mathrm{mass} \%$, and color white. The detailed information on the production and characterization of $\mathrm{ZnSt}_{2}$ can be found in our previous study [15].
Zinc stearate and $n$-paraffin mixture preparation

Test samples were prepared by adding 5, 10 and $25 \mathrm{mg}$ of $\left(\mathrm{ZnSt}_{2}\right)$ into $5 \mathrm{~g}$ of molten wax at the temperature of $130^{\circ} \mathrm{C}$ under vigorous mixing. As the melting point of $\mathrm{ZnSt}_{2}$ is $122^{\circ} \mathrm{C}$ [15], mixing of $\mathrm{ZnSt}_{2}$ and paraffin was carried out above this temperature so that distribution of the additive is provided well by the help of good agitation. The mixture was cooled to room temperature and solid samples were examined for thermal degradation.

\section{Methods}

\section{Analysis by DSC}

The thermal behaviour of paraffin wax and its mixtures with $\mathrm{ZnSt}_{2}$ were determined by DSC (Shimadzu DSC-50) by heating them up to $600^{\circ} \mathrm{C}$ at rate of $10^{\circ} \mathrm{C} \mathrm{min}^{-1}$ under $40 \mathrm{~cm}^{3} \mathrm{~min}^{-1} \mathrm{~N}_{2}$ flow.

\section{Thermogravimetric analysis}

Dynamic thermogravimetric runs were obtained with TG (Setaram Labsys) thermobalance in nitrogen and air atmospheres at a flow rate of $40 \mathrm{~cm}^{3} \mathrm{~min}^{-1}$. The initial mass of samples was about $10-12 \mathrm{mg}$. The dynamic runs were carried out from ambient temperature to $600^{\circ} \mathrm{C}$ at rates of $5,10,15,20^{\circ} \mathrm{C} \mathrm{min}^{-1}$. Thermal decomposition of $\mathrm{ZnSt}_{2}$ was carried out at a rate of $10^{\circ} \mathrm{C} \mathrm{min}^{-1}$ from ambient temperature to $1000^{\circ} \mathrm{C}$.

\section{Kissinger method for analysis of TG data}

The explicit derivations of the methods can be found in the literature [16]. For the sake of brevity, the ultimate operative equations of this technique are given below.

The degradation reaction of polymeric material can be expressed as

$$
\frac{\mathrm{d} \alpha}{\mathrm{d} t}=\beta\left(\frac{\mathrm{d} \alpha}{\mathrm{d} T}\right)=k(T) f(\alpha)
$$

where $\beta$ is the heating rate $\left({ }^{\circ} \mathrm{C} \min ^{-1}\right), \alpha$ the conversion, $k(T)$ the rate constant function of temperature, $T$ absolute temperature $(\mathrm{K})$ and $\alpha$, conversion or fraction decomposed, is defined as

$$
\alpha=\left(W_{0}-W_{\mathrm{t}}\right) /\left(W_{0}-W_{\mathrm{f}}\right)
$$

where $W_{0}$ initial mass of the sample, $W_{\mathrm{t}}$ is the mass of the sample at temperature $t$ and $W_{\mathrm{f}}$ is the final mass at a temperature at which the mass loss is approximately not changed.

Applying $n$ order reaction for the degradation of paraffin wax to obtain 


$$
f(\alpha)=(1-\alpha)^{\mathrm{n}}
$$

The temperature dependence of rate constant of degradation is expressed by Arrhenius as given below

$$
k(T)=A \exp (-E / R T)
$$

Inserting the Eqs (3) and (4) into Eq. (1) gives

$$
\frac{\mathrm{d} \alpha}{\mathrm{d} t}=\beta \frac{\mathrm{d} \alpha}{\mathrm{d} T}=(1-\alpha)^{\mathrm{n}} A \exp (-E / R T)
$$

where $A$ is the pre-exponential factor $\left(\mathrm{min}^{-1}\right), E$ the activation energy of reaction $\left(\mathrm{J} \mathrm{mol}^{-1}\right), R$ is the gas constant $\left(8.314 \mathrm{~J} \mathrm{~mol}^{-1} \mathrm{~K}^{-1}\right)$. Equation (5) is the basic analytical equation for the thermogravimetric data.

This technique involves obtaining the temperature values $T_{\max }$ that occurs at the maximum rate while $\mathrm{d}(\mathrm{d} \alpha / \mathrm{d} t)$ is zero. Differentiation of Eq. (5) with respect to time $(t)$ and setting the resulting expression to zero gives:

$$
\frac{E \beta}{R T_{\max }^{2}}=A n\left(a-\alpha_{\text {max }}\right)^{\mathrm{n}-1} \exp \left(-E / R T_{\text {max }}\right)
$$

The Kissinger method assumes that the product $n\left(1-\alpha_{\max }\right)^{\mathrm{n}-1}$ is independent of $\beta$ and close to 1.0 following expression can be derived:

$$
\ln \left\{\frac{\beta}{T_{\text {max }}^{2}}\right\}=\left\{\ln \frac{A R}{E}+\ln \left[n\left(a-\alpha_{\text {max }}\right)^{\mathrm{n}-1}\right]\right\}-\frac{E}{R T_{\text {max }}}
$$

In this method, activation energy and preexponential factor are obtained by plotting $\ln \left(\beta / T_{\max }^{2}\right) v s .1 / T_{\max }$. The slope of this line gives the $(-E / R)$ and the pre-exponential factor $A$ can be calculated from the intercept $[\ln (A R / E)]$.

\section{Results and discussion}

\section{Characterization of paraffin wax and $\mathrm{ZnSt}_{2}$}

The melting point of paraffin wax is an important parameter that shows the quality of the paraffin based on its components; short or long carbon chains. In some industries wax with low melting point is desired and vice versa for others. DSC has been widely used to characterize different petroleum waxes [17]. As seen in Fig. 1 (curve 1), the paraffin sample that was used, has two endothermic peaks that represent solid-solid and solid-liquid transitions on the DSC curve. The peaks at 39 and $57^{\circ} \mathrm{C}$ belong to orthorhombic to hexagonal transition and solid-liquid transition, respectively [17]. Oil content is also an effective property that influences the melting point of the wax. The oil content of wax sample is given as lower than 1 mass\% in its data sheet. However, it is difficult to determine the contribution of trace amount of oil using DSC technique. Thermal analysis of zinc stearate was conducted by DSC and TG. In Fig. 2,

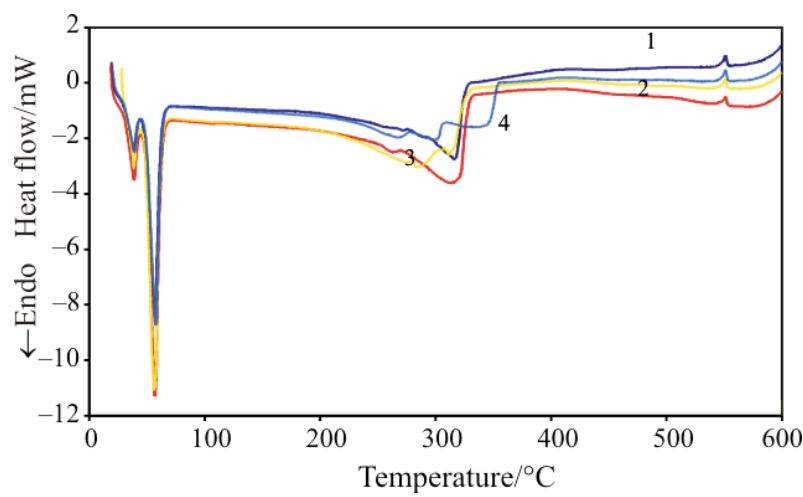

Fig. 1 DSC curves of paraffin wax $\left(\mathrm{ZnSt}_{2} /\right.$ paraffin ratio $(\mathrm{mg} / \mathrm{g})$ as parameter) curves $1-0 ; 2-1 ; 3-2 ; 4-5)$

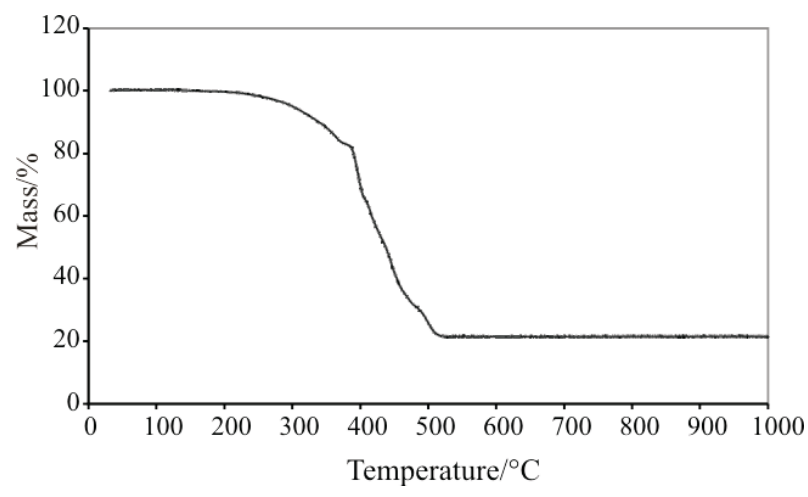

Fig. 2 TG curve of $\mathrm{ZnSt}_{2}$

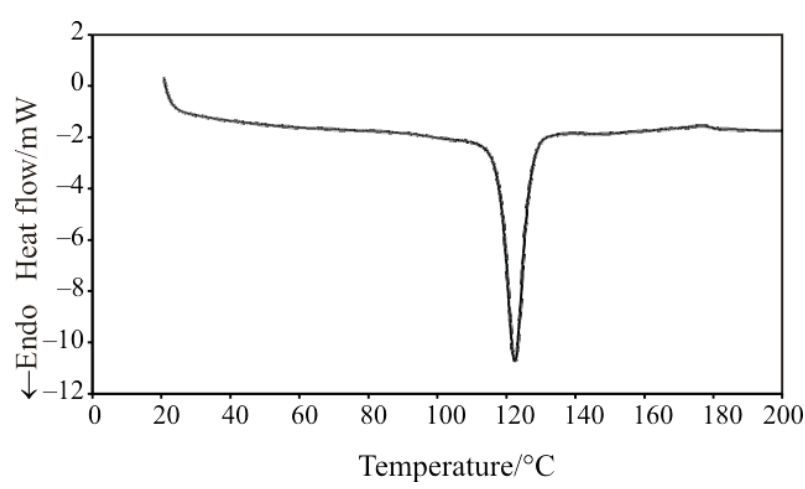

Fig. 3 DSC curve of $\mathrm{ZnSt}_{2}$

pure $\mathrm{ZnSt}_{2}$ started to lose mass above $200^{\circ} \mathrm{C}$ at which degradation starts. The total loss of $\mathrm{ZnSt}_{2}$ occurred as 73 mass \%, and above $550^{\circ} \mathrm{C}$ no mass loss was observed. As seen in DSC curve in Fig. 3, the transition temperature from solid to liquid of $\mathrm{ZnSt}_{2}$ is $122^{\circ} \mathrm{C}$ confirming the literature value [18].

\section{Effect of $\mathrm{ZnSt}_{2}$ on thermal degradation of paraffin wax}

Energy changes during heating

The solid-liquid transition of paraffin wax occurs at $57^{\circ} \mathrm{C}$ as shown in Fig. 1. The paraffin wax thermal 
degradation maximum is at $317^{\circ} \mathrm{C}$ and the maximum occurs at lower temperatures when $\mathrm{ZnSt}_{2}$ was added (curves 2, 3 and 4). $\mathrm{ZnSt}_{2}$ accelerates thermal degradation of the paraffin wax causing degradation at lower temperatures as reported in Table 1. The alkyl group of zinc stearate increases its solubility in molten paraffin and zinc ions having empty d orbitals are expected to accelerate the degradation and oxidation reactions. The heat of fusion and heat of degradation range of samples were 178-204 and $143-185 \mathrm{~J} \mathrm{~g}^{-1}$, respectively. Heat of degradation should be much higher than heat of fusion if all $\mathrm{C}-\mathrm{C}$ bonds break in the main chain. While the heat of fusion is close to the reported values in literature [5], the heat of degradation is much lower than expected. Heat of degradation which is close to heat of fusion indicated that only a small fraction of the $\mathrm{C}-\mathrm{C}$ bonds was broken during the degradation of paraffin wax under experimental conditions studied.

\section{Thermogravimetric analysis}

Figure 4 shows TG curves of paraffin wax samples containing various amounts of $\mathrm{ZnSt}_{2}$ at heating rate of $10^{\circ} \mathrm{C} \mathrm{min}{ }^{-1}$ under air atmosphere. The onset of mass loss, percent mass at $300^{\circ} \mathrm{C}$, and residue are tabulated in Table 2. As seen in Fig. 4 and Table 2, pure paraffin wax starts to decompose above $235^{\circ} \mathrm{C}$ and addition of zinc stearate decreases the decomposition temperature slightly to $220^{\circ} \mathrm{C}$. Samples do not further decompose above the temperature of $550^{\circ} \mathrm{C}$.

The residual masses at $600^{\circ} \mathrm{C}$ for pure wax and wax that contains $\mathrm{ZnSt}_{2}$ were observed as about 3 and

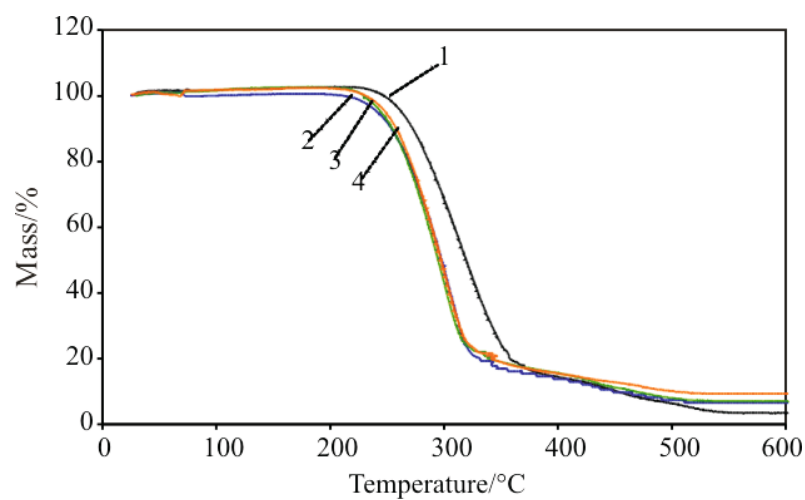

Fig. 4 TG curves of paraffin samples with and without $\mathrm{ZnSt}_{2}$ in air atmosphere at a heating rate of $10^{\circ} \mathrm{C} \mathrm{min}$ $\left(\mathrm{ZnSt}_{2} /\right.$ paraffin ratio $(\mathrm{mg} / \mathrm{g})$ as parameter) curves $1-0$; $2-1 ; 3-2 ; 4-5)$

$7 \%$, respectively. The reason for this higher remaining mass for samples containing $\mathrm{ZnSt}_{2}$ is the effect of zinc on degradation behaviour. Since thermal decomposition products of $\mathrm{ZnSt}_{2}$ are $\mathrm{ZnCO}_{3}$ and $\mathrm{ZnO}$ $[19,20]$ on heating it could increase the amount remained from the decomposition of paraffin wax slightly. As the content of $\mathrm{ZnSt}_{2}$ in paraffin wax is maximum $0.5 \%$, the $\mathrm{ZnO}$ and $\mathrm{ZnCO}_{3}$ that would form from $\mathrm{ZnSt}_{2}$ would be much smaller than $3-7 \%$. In other words the increase of nearly $4 \%$ residual mass should be attributed to increase in amount of soot in presence of zinc compounds in paraffin wax compared to control sample.

Figure 5 shows TG curves of paraffin wax and wax samples containing various amount of $\mathrm{ZnSt}_{2}$ at $10^{\circ} \mathrm{C} \min ^{-1}$ heating rate under nitrogen medium. As

Table 1 Melting and degradation temperatures and energies of paraffine wax and $\mathrm{ZnSt}_{2}$ added paraffines

\begin{tabular}{ccccc}
\hline $\begin{array}{c}\mathrm{ZnSt}_{2} \text { concentration/ } \\
\mathrm{mg} \mathrm{g}^{-1}\end{array}$ & $\begin{array}{c}\text { Melting, } \\
T_{\max }{ }^{\circ} \mathrm{C}\end{array}$ & $\begin{array}{c}\text { Heat of fusion/ } \\
\mathrm{J} \mathrm{g} \mathrm{g}^{-1}\end{array}$ & $\begin{array}{c}\text { Degradation, } \\
T_{\max }{ }^{\circ} \mathrm{C}\end{array}$ & $\begin{array}{c}\text { Heat of degradation/ } \\
\mathrm{J} \mathrm{g}^{-1}\end{array}$ \\
\hline 0 & 57 & 196 & 317 & 178 \\
1 & 57 & 195 & 313 & 153 \\
2 & 57 & 178 & 286 & 185 \\
5 & 57 & 204 & 265 & 143 \\
\hline
\end{tabular}

Table 2 TG results obtained from paraffin and $\mathrm{ZnSt}_{2}$ added paraffin samples degradation at $10^{\circ} \mathrm{C} \mathrm{min}^{-1}$ heating rate

\begin{tabular}{ccccc}
\hline \multirow{2}{*}{ Medium } & $\begin{array}{c}\mathrm{ZnSt}_{2} \text { concentration/ } \\
\mathrm{mg} \mathrm{g}^{-1}\end{array}$ & Onset of mass loss $/{ }^{\circ} \mathrm{C}$ & $\begin{array}{c}\text { Remaining at } \\
300^{\circ} \mathrm{C} / \mathrm{mass}^{\circ}\end{array}$ & $\begin{array}{c}\text { Remaining at } \\
600^{\circ} \mathrm{C} / \mathrm{mass}^{\circ}\end{array}$ \\
\hline \multirow{3}{*}{ Air } & 0 & 235 & 68 & 3 \\
& 1 & 214 & 48 & 6 \\
& 2 & 220 & 43 & 7 \\
& 5 & 221 & 47 & 6 \\
$\mathrm{~N}_{2}$ & 0 & 245 & 87 & 4 \\
& 1 & 235 & 89 & 6 \\
\hline
\end{tabular}


seen in Fig. 5 and Table 2, the addition of $\mathrm{ZnSt}_{2}$ did not make any significant change in the degradation of wax under these conditions. Paraffin decomposition occurred in only one stage as can be seen in Figs 4 and 5.

Kissinger method was employed to obtain the apparent activation energies in air and nitrogen media from several runs with different heating rates $(\beta)$ as shown in Fig. 6.

Figure 7 represents the Kissinger plot of paraffin degraded in air flow. The pre-exponential factor $A$ for the degradation of each sample was calculated using the intercept of the line drawn from experimental data by using Kissinger method. From similar plots prepared for

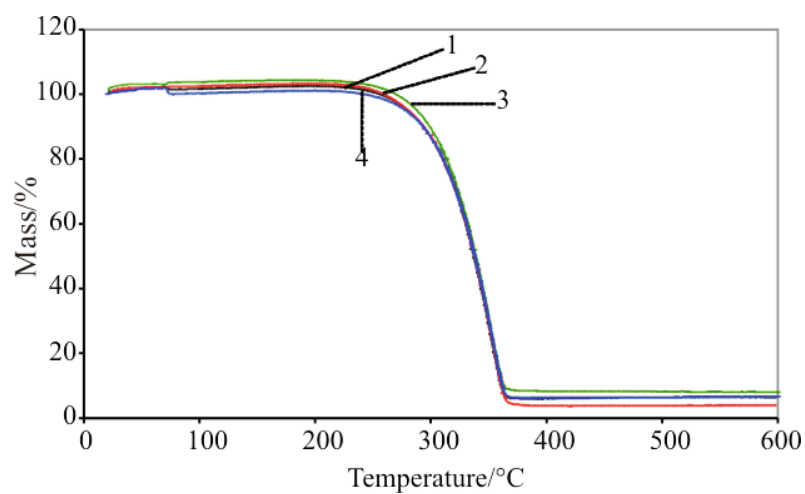

Fig. 5 TG curves of paraffin samples with and without $\mathrm{ZnSt}_{2}$ in $\mathrm{N}_{2}$ atmosphere at a heating rate of $10^{\circ} \mathrm{C} \mathrm{\textrm {min } ^ { - 1 }}$ $\left(\mathrm{ZnSt}_{2} /\right.$ paraffin ratio $(\mathrm{mg} / \mathrm{g})$ as parameter) curves $1-0$; $2-1 ; 3-2 ; 4-5)$

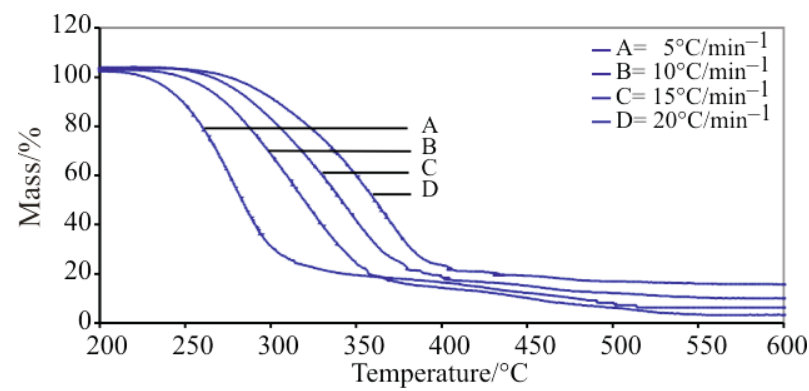

Fig. 6 TG curves of paraffin in air atmosphere at different heating rates samples containing different amount of $\mathrm{ZnSt}_{2}, E$ and $A$ values for each case were determined. It was found that paraffin decomposes faster in air atmosphere than the nitrogen medium by comparing their $E$ values; 37 and $76 \mathrm{~kJ} \mathrm{~mol}^{-1}$, respectively. This result is confirmed in Fig. 8, as paraffin starts to decompose at 235 in air and $245^{\circ} \mathrm{C}$ in nitrogen. It was found that the addition of $\mathrm{ZnSt}_{2}$ into wax in air increased its activation energy from 37 to the mean value of $49 \mathrm{~kJ} \mathrm{~mol}^{-1}$. No such a significant influence of $\mathrm{ZnSt}_{2}$ was observed in nitrogen medium as seen in Table 3 .

The decomposition rate constants, $(k)$ at the temperature of $277^{\circ} \mathrm{C}$ were calculated by Arrhenius equation using the $E$ and $A$ values obtained from Kissinger method in nitrogen and air media. Table 3 represents the $k$ values calculated from the Kissinger technique. Addition of $\mathrm{ZnSt}_{2}$ at a very low level (i.e. up to

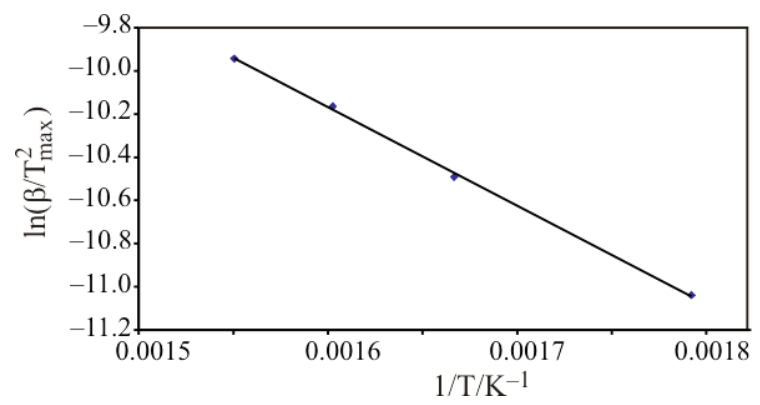

Fig. 7 Kissinger plot of paraffin in air atmosphere

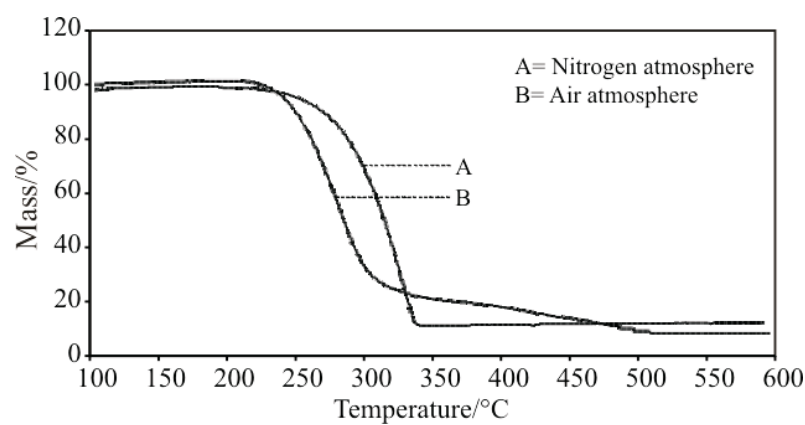

Fig. 8 TG curves of in air and $\mathrm{N}_{2}$ media under $5^{\circ} \mathrm{C}$ min $^{-1}$ heating rate

Table 3 Kinetic parameters calculated from Kissinger equation for the degradation of paraffin and $\mathrm{ZnSt}_{2}$ added paraffin samples

\begin{tabular}{llcccc}
\hline Medium & $\mathrm{ZnSt}_{2}$ concentration $/ \mathrm{mg} \mathrm{g}^{-1}$ & 0 & 1 & 2 & 5 \\
\hline \multirow{4}{*}{ Air } & $E / \mathrm{kJ} \mathrm{mol}^{-1}$ & 37 & 52 & 47 & 49 \\
& $R^{2}$ & 0.99 & 0.98 & 0.99 & 0.99 \\
& $A / \mathrm{min}^{-1} \cdot 10^{-3}$ & 0.26 & 9.63 & 3.42 & 4.96 \\
& $k$ at $277^{\circ} \mathrm{C} / \mathrm{min}^{-1}$ & 0.065 & 0.105 & 0.105 & 0.105 \\
& $E / \mathrm{kJ} \mathrm{mol}^{-1}$ & 76 & 75 & 75 & 70 \\
$\mathrm{~N}_{2}$ & $R^{2}$ & 0.99 & 0.99 & 0.99 & 0.99 \\
& $\mathrm{~A} / \mathrm{min}^{-1} \cdot 10^{-5}$ & 4.38 & 4.07 & 3.92 & 0.67 \\
& $k$ at $277^{\circ} \mathrm{C} / \mathrm{min}^{-1}$ & 0.028 & 0.029 & 0.029 & 0.031 \\
\hline
\end{tabular}


0.5 mass $\%$ ) increased rate constant from 0.065 to $0.105 \mathrm{~min}^{-1}$ in air and from 0.028 to $0.031 \mathrm{~min}^{-1}$ in nitrogen. $\mathrm{ZnSt}_{2}$ greatly accelerated the paraffin decomposition in air.

\section{Conclusions}

All the results obtained from the Kissinger method in this study suggest that the activation energies of thermal degradation of paraffin wax in nitrogen are higher than those of thermal oxidative degradation in air. In other words, paraffin decomposes more easily in air than in nitrogen. The apparent activation energies of wax decomposition in nitrogen and air atmospheres were calculated as 76 and $37 \mathrm{~kJ} \mathrm{~mol}^{-1}$, respectively utilizing Kissinger method. The addition of $\mathrm{ZnSt}_{2}$ in a very low level $(0.1-0.5 \%)$ greatly increased the rate of thermal degradation in air. The decomposition in nitrogen also increased with $\mathrm{ZnSt}_{2}$ addition to a small extent. This was also confirmed by DSC analysis showing lower degradation maximum temperature when $\mathrm{ZnSt}_{2}$ was added.

\section{Acknowledgement}

The authors acknowledge the financial support from State Planning Organization Project 2002 K 120390.

\section{References}

1 O. Sperber, W. Kaminsky and A. Geißler, Petroleum Sci. Technol., 23 (2005) 47.
2 F. T. Alonso, L. A. Angosto Olmos and M. A. Munecas Vidal, Sep. Sci. Technol., 39 (2004) 1577.

3 K. S. Jaw, C. K Hsu and J. S. Lee, Thermochim. Acta, 367-368 (2001) 165.

4 L. Moballegh, J. Morshedian and M. Esfandeh, Mater. Lett., 59 (2005) 2832.

5 H. H Öztürk, Energy Convers. Manage., 46 (2005) 1523.

6 M. A. Karabeyoglu, D. Altman and B. J. Cantwel, U.S. Patent 6,684,624, 2004.

7 P. C. Andersen and T. J. Bruno, Ind. Eng. Chem. Res., 44 (2005) 1670.

8 M. C. Torrente and M. A. Galan, Fuel, 80 (2001) 327.

9 M. Watanabe, M. Tsukagoski, H. Hirakoso, T. Adschiri and K. Arai, AICheE J., 46 (2000) 843.

10 J. Schirmer, J. S. Kim and E. Klemm, J. Anal. Appl. Pyrol., 60 (2001) 205.

11 M. Gürü, U. Karakaya, D. Altıparmak and A. Alıcılar, Energy Convers. Manage., 43 (2002) 1021.

12 C. J. Kolp, D. T. Daly, S. T. Jolley, F. W. Koch, S. H. Stoldt, R. H. Walsh and R. A. Denis, U.S. Patent 5,562,742, 1996.

13 M. V. Kök, and S. Bağc1, Energy Fuels, 18 (2004) 858.

14 M. Alphen, Sci. Total Environ., 244 (1999) 53.

15 M. Gönen, D. Balköse, F. İnal and S. Ülkü, Ind. Eng. Chem. Res., 44 (2005) 1627.

16 T. Hatakeyama and F. X. Quinn, Thermal Analysis Fundamentals and Applications to Polymer Science. $2^{\text {nd }} E d .$, J. Wiley \& Sons, Chichester 1999.

17 S. Kumar, K. M. Agrawal, H.U. Khan and A. Sikora, Petroleum Sci. Technol., 22 (2004) 337.

18 M. S. Akanni and P. C. Nbaneme, Thermochim. Acta, 401 (2003) 199.

19 M. S. Akanni, E. K. Okoh, H. D. Burrows and H. A. Ellis, Thermochim. Acta, 208 (1992) 1.

20 B. S. Randhawa and K. Gandotra, J. Therm. Anal. Cal., 85 (2006) 423.

DOI: $10.1007 / \mathrm{s} 10973-008-9365-8$ 